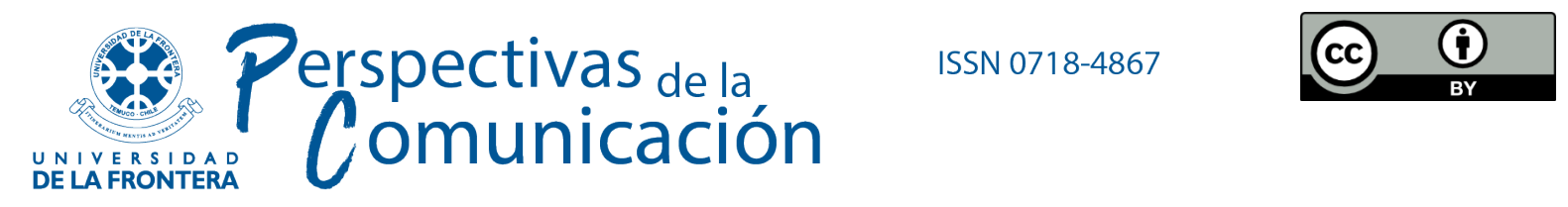

Artículo

\title{
LA TEORÍA DE LA AGENDA SETTING. CRÍTICA EPISTEMOLÓGICA Y PROFUNDIZACIÓN CUALITATIVA A PARTIR DE UN ESTUDIO ANTROPOLÓGICO
}

DOI: POR ASIGNAR

\author{
Dr. Yánder Castillo Salina \\ Universidad de Oriente, Santiago de Cuba, Cuba \\ yandercastillosalina@gmail.com \\ ORCID iD: http://orcid.org/o00o-0003-4149-5620 \\ Dr. Viviana Muñiz Zúñiga \\ Universidad de Oriente, Santiago de Cuba, Cuba \\ vivita@uo.edu.cu \\ ORCID iD: http://orcid.org/oooo-00o1-8476-4136 \\ Dr. Alicia de la Caridad Martínez Tena \\ Universidad de Oriente, Santiago de Cuba, Cuba \\ alicia@uo.edu.cu \\ ORCID iD: http://orcid.org/0000-0003-2119-2286
}

Recibido el 2019-02-05

Revisado el 2020-09-17

Aceptado el 2020-09-27

Publicado el 2021-07-12

\section{Resumen}

El artículo reflexiona sobre la Teoría de la Agenda Setting y algunas de sus carencias teóricoepistemológicas, para explicar las relaciones entre las agendas sociales, motivado por un estudio que se desarrolla en el municipio Mella (Cuba) desde 2015. Se aborda a la relación agenda mediática-agenda pública desde la inmersión etnográfica durante el año 2017. Las técnicas utilizadas son la observación (participante y no participante), los grupos de discusión, las entrevistas a informantes clave, el cuestionario y la revisión documental. Los 
resultados muestran el proceso de relación de agendas en el orden de la vida cotidiana comunitaria, sus lógicas socioculturales y los rasgos distintivos de su modelo socioantropológico. La implementación metodológica etnográfica, así como las reflexiones teóricas emanadas, permiten desarrollar un punto de contraste ante la posición epistemológica positivista de la Teoría de la Agenda Setting.

Palabras clave: agenda setting, medios de comunicación, etnografía, agenda pública, comunicación. 


\title{
THE AGENDA SETTING THEORY. EPISTEMOLOGICAL CRITICIZE AND QUALITATIVE DEEPENING FROM ANTHROPOLOGICAL STUDY
}

\begin{abstract}
The article reflects about the Theory of Agenda Setting and its epistemological scarcities for explaining the relations between social agendas. This reflection is motivated by empirical study in the Mella municipality in Santiago de Cuba developed since 2015. The methodological approaches utilized are the ethnographic and the dialectical-materialistic. The empirical methods are observation (participant and not participant), surveys, discussions groups, key informants' interviews, and documental review. The results show the anthropological model of mediatic and public agendas relations in the communitarian life. Particularly this methodology and theoretic reflections as results of empirical study, are a contrast point of positivist position of the Theory of Agenda Setting.
\end{abstract}

Keywords: agenda setting, media, ethnography, public agenda, communication. 


\section{Introducción}

En la sociedad actual los medios de comunicación desarrollan una función determinante en la articulación de la complejidad social. Establecen representaciones, patrones de consumo, estéticas, axiología, movilización ciudadana, legitimación de la realidad. $\mathrm{Su}$ mediación intersecta las relaciones humanas en un universo cada vez más interconectado y tecnologizado que los autentifica como plataformas de construcción social de la realidad (Orozco, 2010).

La Teoría de la Agenda Setting es una de las perspectivas con mayores resultados en este campo; específicamente en la comprensión de cómo los medios influyen en la selección de los asuntos a los que la colectividad dirige atención. Desde sus primeras implementaciones, en la década de 1970, hasta la actualidad se han desarrollado más de 500 investigaciones que en mayor medida han probado la capacidad de los medios para establecer los temas que los individuos incorporan a su lista de asuntos prioritarios (MacCombs, 2006; Castro, 2014; McCombs \& Valenzuela, 2014).

Recientes sistematizaciones dan cuenta de su expansión hacia múltiples dimensiones del establecimiento de la agenda pública y el papel de actores sociales como los políticos, los grupos de poder y otros medios de comunicación en el proceso (Castro, 2014; McCombs \& Valenzuela, 2014; Vargo, 2018). Entre ellas se advierten nuevas formulaciones para abordar la influencia de los tópicos prominentes en las agendas de los grupos sociales (agenda melding) (Aruguete, 2015), la definición de la agenda cultural a partir de la cobertura de medios especializados (Bantimaroudis \& Zyglidopoulos, 2014), las relaciones entre la agendas de varios medios (intermedia agenda setting) (Muñiz \& Castillo, 2016), la migración de la teoría hacia el campo educativo, el marketing, los deportes (Rodríguez, 2004; McCombs, 2006) entre otros.

La incorporación de campos y categorías al modelo de análisis general, así como la prolífica implementación empírica son algunas de las características distintivas de su modelo de construcción de conocimiento. Sin embargo, no se ha desarrollado una línea de reflexividad lo suficientemente articulada para atender carencias propias de su constitución epistemológica (de las tesis, paradigmas, conceptos, métodos y sus relaciones). Ello ha posibilitado que el desarrollo de la perspectiva apueste por la adición de variables como estrategias para la eliminación de brechas detectadas en su evolución. La crítica teórica, en sentido general, es una de las áreas menos trabajadas de este campo. 
Una reciente sistematización de los estudios de habla inglesa (Kim, Kim \& Zhou, 2017) publicados en las bases de datos Academic Search Premier and Communication y Mass Media Complete, expone solamente 33 investigaciones entre 1972 y 2015 dedicadas a la revisión y la crítica teórica, sin dejar claro las diferencias cuantitativas entre cada categoría. Estos representan el 4,4\% de los 512 estudios recuperados (Kim, Kim \& Zhou, 2017), lo cual contribuye a explicar nuestra conclusión anterior.

Por su parte, José Gallego (2017) ofrece un acercamiento al desarrollo de la teoría en el área latinoamericana. Su trabajo acredita un creciente número de investigaciones a partir de la década del 2000 en las que resulta evidente "la reproducción de los esquemas clásicos y la desatención a varias de las principales limitaciones de la teoría” (p. 87).

Amén de que no se puede distinguir una línea dura de análisis crítico al interior de la Agenda Setting, sí se ha expandido su espectro a partir de fases de estudio en las que se han incluido paulatinamente campos y procesos adyacentes a su objeto central: la selección de la agenda pública. Ello es muestra de que la teoría no ha sido ajena a la profundización del fenómeno que aborda, propiciándose nuevas aplicaciones, incorporaciones metodológicas y un creciente corpus de conocimientos (Casermeiro, 2004; McCombs, 2006; Muñiz, Fonseca \& Caballero, 2016), que han contribuido a la refinación de su aparataje analítico. Empero, los nuevos objetos funcionan a menudo de manera independientes al tradicional (Muñiz \& Castillo, 2018; Ardèvol, Gil \& McCombs, 2020) y no han incorporado la reflexividad teórica a lo interno, ni con las otras líneas. Como consecuencia, se añade el complejo problema de la fragmentación y la integración del conocimiento a la hora de contribuir al modelo teórico general.

A pesar del evidente éxito de la perspectiva de selección de agendas, se consideran adecuadas las observaciones de José Luis Dader (1991) y José Gallego (2015) en relación a que no en todos los casos el ensanchamiento del campo -que en la Agenda Setting ha implicado algunas "absorciones" de conocimientos de otras tradiciones como la agenda building, framing, priming y sociologías de emisores, así como la incorporación paulatina de variables como la temporalidad, el uso y consumo de medios, la comunicación interpersonal y otras- implica mayor profundidad. Sobre todo, si esas "incorporaciones" son asumidas desde sus posibilidades teóricas y empíricas para explicar fenómenos concomitantes al objeto de estudio tradicional y no son aparejadas de la reflexividad teórico-metodológica en torno a los aciertos e insuficiencias de origen.

Perspectivas de la Comunicación - Vol. 14 - No 1 - 2021 - pp. 231-272

Universidad de la Frontera - Chile 
En el libro El poder de la agenda: políticas, medios y públicos, la investigadora argentina Natalia Aruguete (2015) afirma -tal y como lo hicieron Dearing y Rogers, 1996 y McCombs, 2006- que ninguna teoría por sí sola puede explicar la totalidad de la complejidad social, pero persisten inquietudes en el orden metodológico y epistemológico que han estado latentes, así como otras que emergen ante los nuevos medios y las nuevas formas de socialización. Estos criterios son compartidos por una serie de autores desde hace varias décadas (Dader, 1991; Charron, 1995; Dearing \& Rogers, 1996; Tamayo \& Carrillo, 2005; McCombs, 2006; Andréu, 2012; Aruguete, 2015; Castillo, 2015), lo que demuestra que la teoría no ha permanecido carente de revisiones críticas a su formulación e implementación empírica. A pesar de eso, estas y otras observaciones no han encontrado hasta hoy un espacio de debate integrado y sistemático, más allá de pronunciamientos geográficamente distantes y temporalmente aislados.

En la actualidad, existen también algunas preocupaciones en torno a la construcción clásica de la Agenda Setting. Entre ellas el papel de las audiencias en la asimilación de los asuntos propuestos por los medios y los decisores de las políticas, la responsabilidad social de la comunicación de masas y la persistencia cuantitativa y positivista de las metodologías. Particularmente sobre el último aspecto, en una reciente entrevista realizada a Maxwell McCombs (Trigueros \& Lacasa-Mas, 2018, p. 7), el fundador de la teoría expresa que "no hay nada intrínsecamente cuantitativo en la Agenda Setting” por lo que los investigadores cada vez acuden con mayor detenimiento a metodologías cualitativas para explorar nuevas potencialidades. A pesar de esto, el investigador reconoce que esta no es la principal línea en desarrollo.

El presente artículo socializa los resultados de una estrategia de profundización cualitativa a partir de la etnografía, con la cual se persiguió una mayor comprensión de la relación entre las agendas sociales, como parte de la dinámica sociocultural de un municipio cubano. El giro metodológico estuvo motivado por las reflexiones de una etapa precedente en la que se comprobaron algunas de las carencias del modelo analítico de la Agenda Setting detectadas en la revisión bibliográfica, el trabajo empírico y los procesos de reflexividad de la investigación.

El presente trabajo no pretende aportar una metodología - lo que precisaría mayor análisis y ampliación-, sino mostrar las ventajas teóricas y empíricas de la profundización cualitativa, como complemento del enfoque positivista que ha acompañado a la Agenda Setting en sus 
casi cinco décadas. También se expone la necesidad de una línea articulada para la reflexión crítica sobre sus limitaciones y la discusión de propuestas para superarlas.

La investigación toma como objeto de análisis a la relación de las agendas mediática y pública en la construcción social de la realidad comunitaria en el municipio Mella, de la provincia Santiago de Cuba, respecto a los asuntos de relevancia local.

\section{La Teoría de la Agenda Setting: principales postulados y metodologías}

Para comprender la formulación epistemológica de la Agenda Setting es preciso atender al contexto de su surgimiento. Este coincide con la vuelta a los estudios de la influencia de los medios sobre las masas, perspectiva conocida como "efectos limitados" en las investigaciones de la Mass Comunication Research (Wolf, 2004).

Su formulación teórica estuvo mediada por las características de la investigación sobre comunicación masiva en Estados Unidos entre 1920 y 1980, desarrolladas en un marco general de pragmatismo y estudios empíricos. En este contexto, la Agenda Setting se inserta en la vertiente funcionalista de atención a los efectos mediáticos y el positivismo (Fernández \& Tardivo, 2016). Fue de las primeras teorías en tratar el papel de la comunicación masiva en la construcción social de la realidad (Berra \& Fernández, 2005).

Sus bases epistemológicas fueron recuperadas por Maxwell McCombs \& Donald Shaw (1972) de obras trascendentales dentro del paradigma de investigación en comunicación de masas. Entre ellas figura la idea de Walter Lippman (1922) de que los medios producen imágenes del mundo que median las percepciones de los individuos. También la premisa de Bernard Cohen (1963) de que los medios no siempre pueden decirle a la gente qué pensar, aunque pueden ser más exitosos en establecer sobre qué pensar.

Para comprobar estas ideas, el estudio seminal (McCombs \& Shaw, 1972) recurrió a la correlación de las temáticas destacadas por medios de alta audiencia y los asuntos relevantes para un grupo de votantes indecisos de la comunidad de Chapel Hill (Carolina del Norte, Estados Unidos). El resultado fue un alto nivel de coincidencia entre las agendas y, por tanto, la principal conclusión fue la prueba de que los medios definieron la agenda pública. Este estudio sentó la metodología tradicional a partir de las técnicas del cuestionario, el análisis de contenido y la correlación estadística. 
En su devenir, la Agenda Setting ha comprobado con rotundo éxito tres hipótesis centrales. Estas tesis están relacionadas con los niveles en que ocurre la transferencia de relevancia entre las agendas sociales, fenómeno que se denomina "establecimiento de la agenda" (Castro, 2014; Aruguete, 2015), a saber:

- Primer nivel: Los individuos excluyen de sus conocimientos lo que los medios excluyen de sus contenidos. En esta dimensión ocurre la transferencia de los asuntos generales o issues presentados en la agenda de los medios hacia aquellos destacados por el interés público.

- Segundo nivel: Según sea la forma en que los medios presentan un tema, cómo lo enfatizan, así la audiencia le atribuirá importancia. Se aborda la transferencia de los atributos con que se encuadran los asuntos, en términos de particularización y marcos afectivos.

- Tercer nivel: Los medios pueden establecer cómo relacionar unos asuntos con otros. También conocido como Nivel de Agenda Setting en Red. Explica cómo las coberturas periodísticas de medios informativos digitales establecen mapas asociativos entre los temas.

El estudio de estos niveles no ha estado equiparado en el tiempo. Su enunciación corresponde a cinco fases de estudio, a partir de la incorporación de campos y categorías. Estas etapas son presentadas en detalles por una extensa lista de sistematizaciones (Vara, 2001; Casermeiro, 2004; Rodríguez, 2004; McCombs, 2006; Aruguete, 2015; Castro, 2014), por lo que solo serán enunciadas a fin de que el lector no familiarizado cuente con una idea generalizadora de la construcción epistemológica de la teoría. De igual manera, el análisis de las carencias discutidas en un próximo apartado puede brindar al lector una mayor información sobre su desarrollo.

Una primera etapa se encargó de examinar estadísticamente la transferencia de objetos (issues) de la agenda de los medios a la agenda del público. McCombs (2006) señala que la simplicidad de la hipótesis inicial contribuyó a la creciente aparición de estudios comprobatorios en diversos escenarios sociopolíticos, lo que dio lugar a nuevos hallazgos y preguntas que propiciaron nuevas fases de investigación.

Durante la segunda etapa se introdujo el estudio de factores de naturaleza psico-social que determinan la influencia mediática sobre los públicos, denominados "condiciones contingentes". Se inició de esta forma al ensanchamiento del campo teórico en la búsqueda de una mayor explicación de la hipótesis inicial. Se demostró la plausibilidad del enfoque para incorporar categorías y metodologías provenientes de ciencias tales como la Sociología, la Psicología y las Ciencias Políticas. Entre los factores más estudiados en la actualidad se encuentran la necesidad de orientación, la exposición a los medios, los diversos tipos de 
asuntos y medios de masas, entre otros que implican modos particulares de consumo y socialización de ideas (Aruguete, 2015; Muñiz \& Castillo, 2018).

Por su parte, la tercera etapa de la investigación puso atención al segundo nivel de la transferencia de relevancia entre las agendas, demostrándose la influencia mediática en la selección de los encuadres con que los sujetos asumen los asuntos. Esta fase comprobó una mayor influencia mediática al establecer no solo sobre qué asuntos prestar atención sino también cómo pensar sobre los mismos (McCombs \& Valenzuela, 2014). Ante este ensanchamiento teórico emergió como pregunta ¿quién establece la agenda de los medios?, dando lugar a la cuarta fase de investigación, la que extendió el campo a las mediaciones sobre los emisores y al estudio de la agenda política. En esta etapa se formula el modelo de capas de cebolla para el abordaje de la agenda mediática (McCombs, 2006), aunque también han sido frecuentes otros modelos de agenda building y sociología de emisores, como el de Jerarquías de Influencias de Shoemaker y Reese (2014) (Muñiz \& Castillo, 2018).

Por último, la quinta etapa aborda con mayor profundidad las condicionantes sociológicas de la fijación temática, así como la extensión de la Agenda Setting hacia nuevos campos. En paralelo se desarrollan investigaciones sobre el entorno digital y el modelo de agenda setting en red (NAS Model), el cual abre las posibilidades de aplicación al entorno digital (McCombs, 2006; Castro, 2014; Aruguete, 2015).

Es importante destacar que cada fase no ha supuesto la superación de las precedentes, sino la extensión a nuevas áreas. Ello ha conllevado a que en la actualidad se estudien en paralelo y, en algunos casos, los diseños se extiendan a más de una (Aruguete, 2015). McCombs, Shaw \& Weaver (2014) distinguen dos tendencias de desarrollo de la Agenda Setting. Una centrífuga está abocada a trascender el original dominio de la construcción de los asuntos públicos a partir de la incorporación de nuevos actores y; una centrípeta, profundiza en las categorías que median la transferencia de temáticas relevantes entre las agendas.

Muñiz y Castillo (2018), al recorrer las metodologías utilizadas, destacan la prominencia de los métodos cuantitativos. Los factores que inciden en el establecimiento de la agenda mediática sobre el público (condiciones contingentes) se estudian desde un diseño fundamentalmente cuantitativo a partir de cuestionarios aplicados a grandes muestras, mientras que la formación de la agenda de los medios responde principalmente a 
metodologías mixtas y otras estrictamente cualitativas emanadas de la tradición de Sociología de Emisores (Casermeiro, 2004; McCombs \& Valenzuela, 2014).

\section{Enfocar las carencias de la Agenda Setting: una prioridad epistemológica}

Las críticas identificadas en la revisión de la literatura se relacionan con el orden metodológico y la necesidad de profundizar en variables que intervienen en la ocurrencia del fenómeno (Dader, 1991; Bouza, 2012; Aruguete, 2015; Gallego, 2015, 2016). Salvo en el análisis de José Luis Dader (1991), los señalamientos no se sustentan en la integración de las cuestiones gnoseológicas, metodológicas y epistemológicas para analizar la formulación de la teoría en su sentido holístico y complejo.

En primer lugar, la Agenda Setting reproduce los modelos del positivismo y por tanto pone atención al dato cuantitativo y a la parte cuantitativamente verificable de la realidad. En la mencionada entrevista con McCombs (Trigueros \& Lacasa-Mas, 2018), este último expresa que la articulación metodológica tradicional responde a un contexto en que las Ciencias Sociales utilizaban esta metódica. De hecho, a lo largo de la historia de la Agenda Setting se han incorporado métodos cualitativos (Trigueros \& Lacasa-Mas, 2018). Estas incorporaciones se integraron con una teoría ya formulada y en crecientes grados de implementación empírica, por lo que han servido de complemento, pero no han modificado sustantivamente las tesis y formas de apropiación de la realidad tradicionales.

Para Dader (1991), el problema de la Agenda Setting ha radicado en la centralidad de sus afirmaciones: el medio define la agenda pública y no a la inversa. En la actualidad esta visión ha sido matizada hacia una concepción menos determinista: bajo determinadas circunstancias es probable que los asuntos destacados por los medios sean aceptados por los públicos como prominentes (McCombs \& Valenzuela, 2014; Aruguete, 2015). Lo anterior ha conllevado a que se discutan posibles líneas de análisis en la que se incorporen nociones más dialécticas en torno al papel de los medios masivos en la construcción de la realidad (Trigueros \& Lacasa-Mas, 2018). En cierta medida, lo anterior reconoce la necesidad de trascender los marcos del positivismo y el mediacentrismo.

Muñiz y Castillo (2018) destacan que la articulación de la Teoría de la Agenda Setting posee al menos tres aspectos que tienden a ser polémicos: el contexto social no se considera una condición imprescindible para el estudio de las relaciones entre agendas; los actores sociales no son vistos desde su capacidad para producir sentido a partir de las condiciones de su 
entorno; y, la teoría no busca transformar la realidad que describe, asumiendo una postura descriptivo-explicativa de las relaciones entre las agendas (p. 130). Estas cuestiones están estrechamente relacionadas con el empirismo, el funcionalismo y el positivismo que aún condiciona su desarrollo.

Uno de los temas menos debatidos resulta la utilización de la estadística inferencial y específicamente de los coeficientes de correlación (rho Spearman, Rozell-Campbell baseline, rho Pearson etc.- (Muñiz \& Castillo, 2018)). Estos no calculan causalidad entre dos variables, sino sus niveles de relación y linealidad, por lo que la alta correlación entre dos agendas no necesariamente implica la existencia de causalidad entre las mismas. La interpretación de la agenda mediática como independiente y determinista de la agenda pública está relacionada con los enfoques tradicionalmente mediacéntrico con que la Mass Comunication Research ha posicionado su modelo de construcción de conocimiento (Fernández \& Tardivo, 2016).

En el caso de Cuba, algunos estudios apuestan por contrastar los resultados de las correlaciones a partir de inmersiones cualitativas, en las que se pregunta a la gente mediante qué vías ha recibido los asuntos que integran su agenda. Cuando las fuentes de los asuntos de la agenda pública coinciden con los medios estudiados y los resultados de las correlaciones son significativos, puede afirmarse que estos medios "establecieron la agenda" (Castillo, 2015; 2018; Muñiz, Fonseca \& Caballero, 2016).

Este asunto ha sido preocupación de algunos investigadores (Aruguete, 2015) y se ha pretendido matizar a partir de la inclusión de un conjunto de variables (la temporalidad o el uso de medios -por ejemplo-) (McCombs, 2006), que posibilitan cierto grado de apropiación de las retroalimentaciones entre las agendas. Sin embargo, incluso en los últimos tiempos, es muy común recuperar estudios que apuestan por la correlación y el examen estadístico de la composición temática de las agendas, como instrumento exclusivo para fundamentar hallazgos de investigación. Una reciente revisión crítica a los estudios publicados en revistas científicas españolas y las Tesis Doctorales defendidas en ese país, concluye que "la mayoría de los trabajos en el período 2014-19 se apoyan en el modelo más básico de la teoría, y muy pocos se centran en algunas de las extensiones del modelo original" (Ardèvol, Gil \& McCombs, 2020, p. 14). Esta conclusión coincide con los resultados de Gallego $(2015,2017)$ y las observaciones realizadas por los autores de este trabajo. 
Por otro lado, como se abordó al principio del artículo, la inclusión de variables como estrategia de profundización en torno a un fenómeno complejo como el establecimiento de la agenda, puede ser un arma de doble filo. Cubrir su amplitud implicaría tener en cuenta una infinidad de categorías y su actuación en contextos específicos: el uso de medios y la comunicación interpersonal pueden no funcionar de la misma manera en la sociedad capitalista urbana que en contextos rurales de países emergentes; quizá en estas últimas comunidades las variables determinantes del establecimiento de la agenda puedan no coincidir con las tradicionalmente planteadas por la teoría.

La contrastación de resultados con la hipótesis funcionalista y de altos grados de centralidad como la que formula esta teoría, implica diatribas epistemológicas, que hasta el momento no se han desarrollado consistentemente en la comunidad de investigadores. Otras perspectivas de mayor abstracción (interaccionismo simbólico, fenomenología), apuestan por formas más atentas a los núcleos de lo social como estrategia de profundización (y por tanto rastreables en cualquier formación socio-cultural), como pueden ser las prácticas, hábitos, mediaciones, estructuras, relaciones e interacciones etc., a partir de las cuales se objetivan en una realidad situacional las categorías tradicionalmente planteadas por la Agenda Setting u otras que pudieran intervenir en el establecimiento de las agendas.

Dader (1991), aludiendo a las carencias sociológicas del positivismo como paradigma de la Agenda Setting, manifiesta la necesidad impostergable de sobrepasar los problemas lógicosdeductivos del que se nutren los conocimientos “abstractos", recuperados por investigaciones de corte micro y metodologías heterogéneas y cuestionables precisamente por permanecer al margen de conocimientos emanados de tradiciones con mayor grado de solidez al interior de la sociología y la filosofía.

Este autor, al referirse a las posiciones fundamentalmente empíricas de las escuelas norteamericanas de comunicación y las perspectivas más filosóficas de las escuelas europeas en el estudio del objeto "medios de comunicación y construcción social de la realidad", develó -a nuestro juicio- la principal carencia de la teoría para explicar la complejidad del fenómeno de agenda setting:

la inexistencia de una explicación sistemática del orden social y sus agentes constructores que, explicando el cómo y el porqué de las estructuras de reproducción y construcción del 
"mundo de la vida", permiten de paso iluminar e integrar el fenómeno de la "canalización periodística" [agenda setting] en una interpretación de orden superior”. (Dader, 1991, p. 9)

$\mathrm{Al}$ respecto, Charron (1995) coincide en la necesidad de definir mejor los parámetros según los cuales se eligen los temas de las agendas. Estos corresponden a la esfera de fenómenos de la cultura y la ideología, que los hace "objeto de fuerzas sociales e históricas que las técnicas de investigación empíricas difícilmente pueden captar, pero que no por ello son menos importantes para llegar a conocer la realidad pública en un determinado momento histórico" (p. 82).

El desarrollo de un marco de explicación de las relaciones de agendas en su complejidad socio-antropológica permitiría insertar a la Agenda Setting al interior de una mayor clarificación de los hechos sociales a los que enfoca. Lo anterior es primordialmente necesario, si se considera, al igual que su creador, Maxwell McCombs, que la Agenda Setting se ha convertido en una teoría que explica las relaciones entre las agendas sociales, más allá de los efectos producidos por la comunicación de masas (Trigueros \& Lacasa-Mas, 2018). Aunque consideramos que la teoría podría lograr este curso epistemológico (con sus necesarias reorientaciones), o acaso trascender a una nueva formulación, no compartimos que este sea su estado actual.

El estudio de una comunidad cubana desde 2015, como parte de la investigación doctoral del autor principal del artículo, permitió comprobar algunas de las carencias teóricas discutidas. En el próximo apartado presentamos las conclusiones más relevantes de etapas precedentes (2015-2016), así como las potencialidades de la estrategia etnográfica para la profundización teórica, metodológica y empírica.

\section{Reflexiones sobre una experiencia investigativa precedente. El método etnográfico como alternativa}

El estudio precedente a las reflexiones empíricas que presenta este trabajo siguió la metodología tradicional de la Agenda Setting. Fue desarrollado entre septiembre de 2015 y diciembre de 2016 y enfocó a la relación entre los asuntos relevantes en las agendas de la ciudadanía del municipio Mella y aquellos destacados en la agenda mediática de la emisora local Radio Titán, único medio de comunicación de masas existente en el municipio. El foco de análisis fue el establecimiento de la agenda pública respecto a los asuntos de relevancia local destacados por el medio (Castillo, 2018).

Perspectivas de la Comunicación - Vol. 14 - No 1 - 2021 - pp. 231-272

Universidad de la Frontera - Chile 
Se comprobó una lejanía temática sustancial (resultados correlativos nulos) entre las agendas. Posteriormente, con la utilización de métodos cuantitativos (cuestionarios) y cualitativos (grupos focales y entrevistas) se logró establecer la influencia de algunas "condiciones contingentes" sobre el proceso, que si bien facilitaron la aproximación a la relación agenda mediática-agenda pública, abrieron nuevas preguntas ante la peculiar dialéctica sociocultural de la comunicación mediática del municipio (presentada más adelante): aunque los índices de consumo y exposición a los mensajes son estadísticamente altos, persisten divergencias respecto a la credibilidad de los temas presentados y la funcionalidad atribuida por los comunitarios y los actores institucionales de la sociedad local al medio (Castillo, 2018).

Por su parte, se develó la necesidad de incorporar al análisis el contexto social como un marco de explicación de las formas y magnitudes de la relación entre las agendas. El contexto comunitario se inserta en constante relación con un sistema de referencia macrosocial. La relación micro-macro se expresa en muchos sentidos. Entre ellos se influye en la estructuración social y el orden de la cultura de comunicación, consumo y las relaciones sociales comunitarias. Estos últimos factores inciden sobre las formas en que se consume el medio local, en que ocurre el proceso de apropiación de sus contenidos y las prácticas de socialización y discusión colectiva.

Por tanto, se consideró la pertinencia de estudiar estas condicionantes como una dimensión sociocultural en que ocurre la interrelación entre las agendas abordadas y no como meros factores determinantes del establecimiento, tal y como, para el caso del marco contextual, han propuesto autores como José Gallego (2015) y Jaime Andréu (2012). Lógicamente, estas dinámicas no pueden ser estudiadas con exclusividad de instrumentos cuantitativos dada su complejidad, pues en buena medida responden a cómo los individuos y los actores comunitarios han institucionalizado, habitualizado y significado las lógicas que articulan el mundo de la vida comunitaria.

En la búsqueda de una nueva mirada se tuvo en cuenta que la noción funcionalista de que los medios "funcionan" como selectores de la agenda del público, puede traer consigo una visión sesgada al incitar a los investigadores a centrar las miradas en una fracción (selección de la agenda pública) de un fenómeno social más complejo (relaciones entre agendas sociales). Es decir, centrada en la determinación de los efectos, más que en su comprensión como parte de las dinámicas sociales. 
Para profundizar en la complejidad sociocultural que media la forma en que se relacionan las agendas mediática y pública, se hizo necesario replantear la estrategia metodológica y epistemológica, por lo que se enfocó al objeto de investigación a partir del rejuego entre estructuras y significados institucionalizados en la comunidad para la definición de los asuntos públicos y a sus relaciones con la sociedad macro en la que se inserta.

Se apostó por una estrategia de inmersión antropológica a partir de un diseño etnográfico. La antropología es la ciencia del holismo (Osorio, 2002). Facilitó la calada cualitativa orientada al conocimiento en profundidad de la sociedad y su cultura, desde la perspectiva de sus miembros (Guber, 2004) (en este caso actores del medio local y la ciudadanía). En el abordaje de la relación medio-público el método etnográfico ha demostrado grandes ventajas y ha sido una de las columnas vertebrales de los estudios de comunicación y cultura en Latinoamérica (Martín-Barbero, 2005).

Sobre este particular, Torre (1997) destaca que permite un "acceso mínimo a la realidad antropológica en comunicación” (p. 149). Para estudiar el caso específico de una “antropología de la radio”, Paredes (2005) expresa que la etnografía posibilita mayor profundidad científica a "cómo las audiencias construyen los significados de la radio como una cultura y a la mirada intercultural de la relación tecnología y pensamiento" (p. 5). Mientras, Rosemberg (2017) comprueba su pertinencia y sus retos para el estudio de los emisores y particularmente para el análisis de redacciones periodísticas.

Por otro lado, estudios antropológicos sobre comunicación de masas (Ardèvol, 1998; Trindade \& Silva, 2009) reconocen que como parte de una "nueva antropología" es posible acudir a una variada gama de técnicas y metodologías (cuantitativas y cualitativas) compactadas en los diseños etnográficos, los cuales se sustentan en la experiencia directa del antropólogo en el contexto estudiado. Esta combinación de métodos permite mayor comprensión del cuadro general de la sociedad.

Aunque la etnografía se utiliza como complemento a la formulación epistémica y metodológica de la Agenda Setting, para mayor profundidad cualitativa, no se pierden de vista sus principales retos y dificultades. Si bien este análisis no se desarrolla en este trabajo -por lógicas razones de espacio-, sí se tuvo en cuenta en el proceso de la investigación. Particularmente aquellos señalados por Guber (2004), Trindade y Silva (2009) y Rosemberg (2017). 
Atendiendo a estas características, consideramos que los tradicionales métodos cuantitativos de la Teoría de la Agenda Setting no entran en conflicto con técnicas más cualitativas como la observación participante, las entrevistas y las historias de vida, sino más bien contribuyen con su complementariedad.

\section{Aspectos metodológicos y límites del estudio}

El artículo presenta los resultados de una fase de la investigación de mayor rigor cualitativo, acontecida entre enero y diciembre de 2017. Los métodos y técnicas aplicadas en esta etapa fueron complementados con abordajes precedentes y con otros estudios sobre el campo de investigación a partir de la técnica de revisión de documentos.

Los métodos generales utilizados fueron el etnográfico y el dialéctico-materialista los que permitieron apropiarse de la realidad social del municipio en su sentido histórico, dialéctico y sociocultural.

Se estudiaron las categorías "condiciones contingentes" (Muñiz \& Castillo, 2018) para el análisis del fenómeno desde la audiencia. Las condiciones contingentes abordadas fueron el consumo del medio, la cantidad de temas en la agenda pública individual, la necesidad de orientación sobre los problemas locales, el interés por lo asuntos locales, la comunicación interpersonal y los espacios de discusión sobre los asuntos de relevancia pública.

Por su parte, las variables planteadas en el "modelo de jerarquía de influencias" (Shoemaker \& Resse, 2014) se utilizaron para estudiar la formación de la agenda mediática1 ${ }^{\text {. Resultó }}$ significativa para la articulación metodológica la propuesta presentada por Viviana Muñiz y Yánder Castillo (2018) para la aplicación de la Teoría de la Agenda Setting al caso cubano. Los resultados empíricos se anclaron a la etnografía del contexto sociocultural.

Estos elementos, ampliamente desarrollados por las fases y niveles de la teoría, sirvieron como base para explicar los rasgos distintivos del modelo de relación entre las agendas 
mediática y pública. Por su parte, la investigación etnográfica permitió su análisis desde dimensiones como la cultura de comunicación local, las relaciones entre la sociedad micro y el contexto de referencia (macro) y la construcción histórica de la antropología comunicacional comunitaria.

En este aspecto, la metodología y epistemología tradicional de la Agenda Setting se redimensionó, al menos, en tres sentidos:

- Se atiende a la configuración de las relaciones entre las agendas mediática y pública y no únicamente a la transferencia de los asuntos de la agenda mediática a la agenda pública.

- Se explican los resultados de la correlación entre las agendas desde la descripción de las formas estructurales y socioculturales que caracterizan sus relaciones al interior del modelo antropológico de construcción social de la realidad comunitaria.

- Las técnicas cuantitativas muestran un "estado" del hecho social, mientras las cualitativas permiten su comprensión anclada a la realidad y cultura comunitaria.

En la siguiente tabla (Tabla 1) se resumen los objetivos, muestras, periodo de aplicación y unidades de análisis de los métodos empíricos aplicados.

Tabla 1. Datos sobre las técnicas aplicadas.

\begin{tabular}{|c|c|c|c|c|}
\hline Técnica & Objetivo & $\begin{array}{l}\text { Unidad de } \\
\text { análisis }\end{array}$ & Muestra & $\begin{array}{l}\text { Temporali- } \\
\text { dad de } \\
\text { aplicación }\end{array}$ \\
\hline $\begin{array}{l}\text { Observación } \\
\text { no } \\
\text { participante }\end{array}$ & $\begin{array}{l}\text { Determinar rasgos } \\
\text { distintivos de la } \\
\text { dinámica de } \\
\text { relación entre las } \\
\text { agendas del medio } \\
\text { y el público en el } \\
\text { contexto } \\
\text { sociocultural del } \\
\text { municipio. }\end{array}$ & $\begin{array}{l}\text { 1-Barrios del } \\
\text { municipio. } \\
\text { 2-Plazas, } \\
\text { mercados y } \\
\text { otros espacios } \\
\text { públicos. } \\
\text { 3-Reuniones de } \\
\text { programación } \\
\text { de la emisora } \\
\text { 4-Desarrollo de } \\
\text { los programas } \\
\text { de la radio local. }\end{array}$ & \begin{tabular}{|lll}
$\mathbf{1}$ y $2-15$ barrios de \\
las 7 demarcaciones \\
del municipio. \\
3- 55 reuniones de \\
Programación. & \\
4-Todos & los \\
programas & \\
informativos & del \\
medio (3).
\end{tabular} & $\begin{array}{l}\text { Enero -Mayo } \\
2017\end{array}$ \\
\hline
\end{tabular}




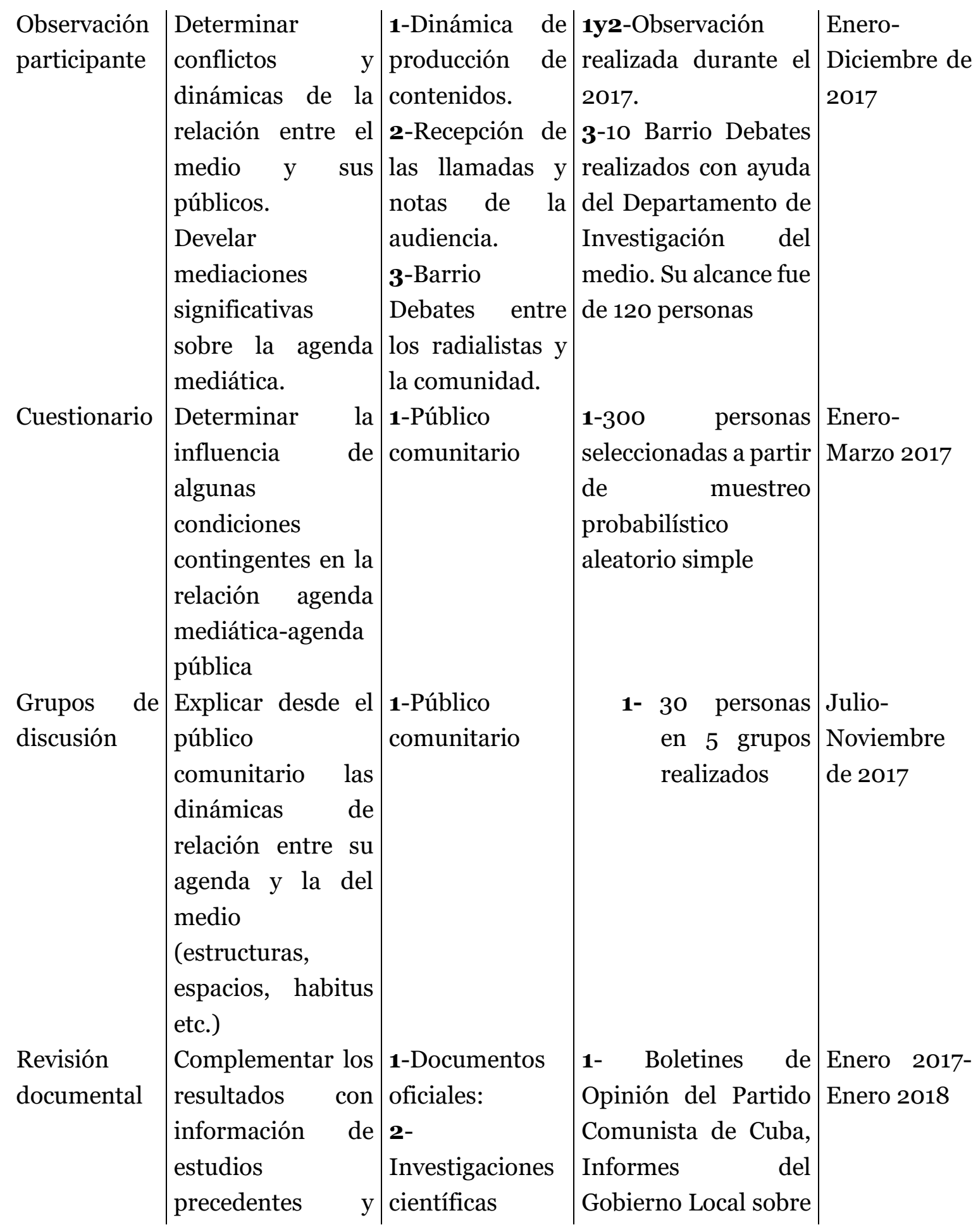




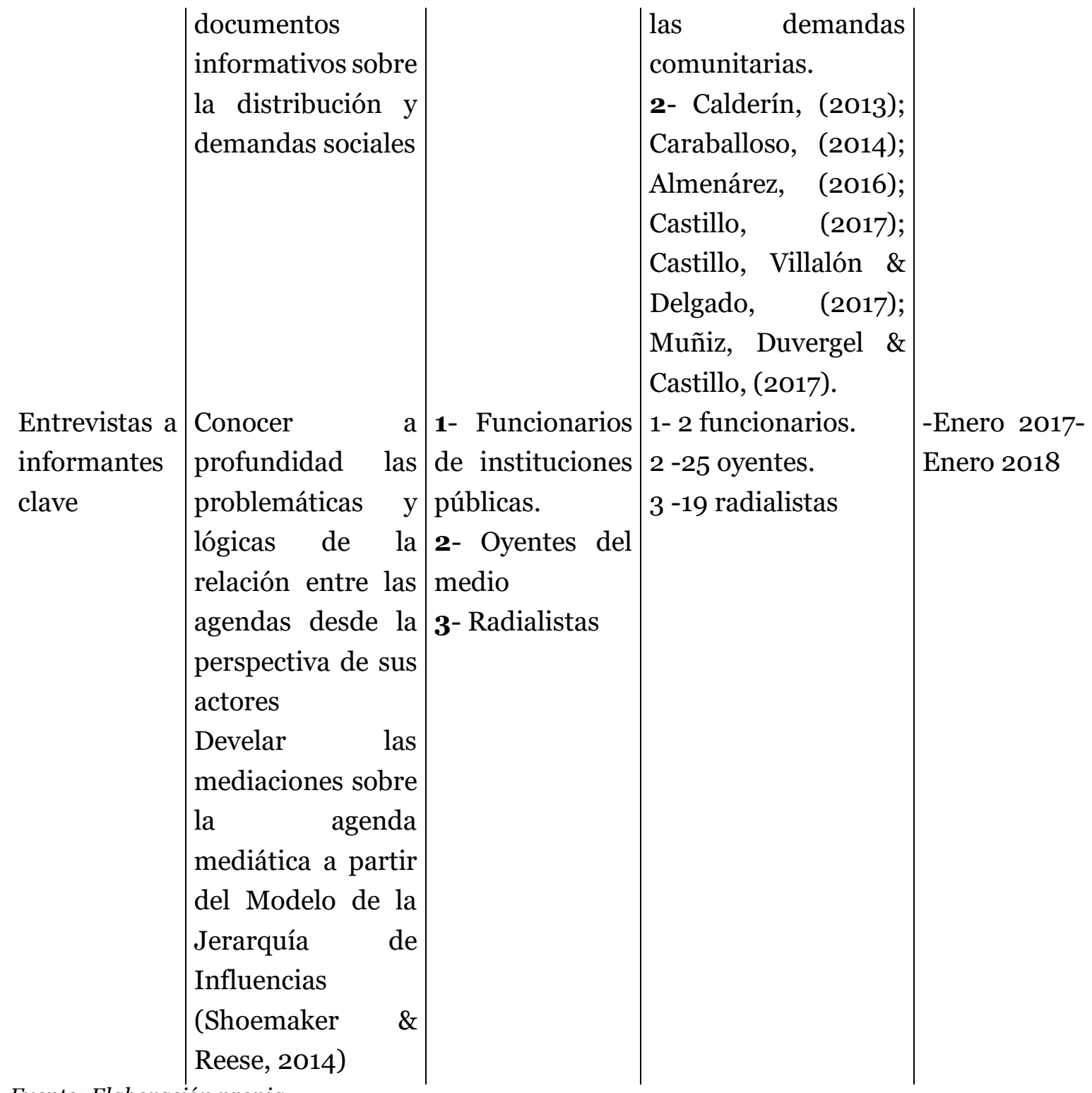

Fuente: Elaboración propia

Para la aplicación de los instrumentos cuantitativos se determinó una muestra de 300 personas, tomando como margen de error al $5 \%$ y nivel de confianza del $90 \%$, criterios válidos en Ciencias Sociales (Hernández, Collado \& Baptista, 2014). Debido a las limitaciones económicas y de recursos humanos para la aplicación de los instrumentos se excluyeron a las personas menores de 18 años y con algún tipo de discapacidad mental. La 
población restante para el cálculo de la muestra fue de 20.684 habitantes. Las estadísticas se tomaron de informes de la oficina de Planificación Física de la localidad.

El tipo de muestreo fue aleatorio simple, ya que no se persiguió el análisis segmentado de la población. De hecho, los estudios que han enfocado a las denominadas variables demográficas como condiciones contingentes, rara vez han logrado resultados concluyentes y generalizables (Vara, 2001; Casermeiro, 2004; Rodríguez, 2004; Aruguete, 2015).

Los grupos de discusión siguieron una estrategia de selección intencional de los participantes. Se trató de incorporar visiones de diferentes grupos etarios y comunidades rurales y urbanas, que permitiera asomarse a la diversidad social, amén de que no constituyó objetivo de la investigación la segmentación del público. Su composición se muestra en la siguiente tabla (Tabla 2). 
Tabla 2. Composición de los grupos de discusión.

\begin{tabular}{|c|c|c|c|c|c|c|c|}
\hline & $\begin{array}{l}\text { Grupo } \\
1\end{array}$ & $\begin{array}{l}\text { Grupo } \\
2\end{array}$ & $\begin{array}{l}\text { Grupo } \\
3\end{array}$ & $\begin{array}{l}\text { Grupo } \\
4\end{array}$ & $\begin{array}{l}\text { Grupo } \\
5\end{array}$ & Total & $\%$ \\
\hline $\begin{array}{l}\text { Cantidad de } \\
\text { integrantes }\end{array}$ & 5 & 7 & 5 & 6 & 7 & 30 & 100 \\
\hline Hombres & 3 & 4 & 1 & 3 & 3 & 14 & 47 \\
\hline Mujeres & 2 & 3 & 4 & 3 & 4 & 16 & 53 \\
\hline $\begin{array}{l}\text { Entre } 18 \text { y } \\
25 \text { años }\end{array}$ & 2 & 1 & O & 1 & 4 & 8 & 27 \\
\hline $\begin{array}{l}\text { Entre } 26 \text { y } \\
40 \text { años }\end{array}$ & 2 & 2 & 3 & 3 & 2 & 12 & 40 \\
\hline $\begin{array}{l}\text { Entre } 41 \text { y } \\
60 \text { años }\end{array}$ & 1 & 2 & 2 & 1 & o & 6 & 20 \\
\hline $\begin{array}{l}\text { Entre } 61 \text { y } \\
70 \text { años }\end{array}$ & o & 2 & o & 1 & 1 & 4 & 13 \\
\hline Lugar & $\begin{array}{l}\text { Sede } \\
\text { Deport } \\
\text { es }\end{array}$ & $\begin{array}{l}\text { CDR } 3 \\
\text { Palmar } \\
\text { ito }\end{array}$ & $\begin{array}{l}\text { Secund } \\
\text { aria } \\
\text { Baragu } \\
\text { á }\end{array}$ & $\begin{array}{l}\text { UEB } \\
\text { Alimen } \\
\text { taria }\end{array}$ & $\begin{array}{l}\text { Hospit } \\
\text { al }\end{array}$ & - & - \\
\hline Duración & $30 \mathrm{~min}$ & $45 \mathrm{~min}$ & $40 \mathrm{~min}$ & $45 \min$ & $45 \mathrm{~min}$ & - & - \\
\hline Fecha & $\begin{array}{l}7 / 02 / 2 \\
017\end{array}$ & $\begin{array}{l}13 / 02 / \\
2017\end{array}$ & $\begin{array}{l}15 / 03 / \\
2017\end{array}$ & $\begin{array}{l}23 / 03 / \\
2017\end{array}$ & $\begin{array}{l}18 / 04 / \\
2017\end{array}$ & - & - \\
\hline
\end{tabular}

Fuente: Elaboración propia

Se reconoce que al centrarnos en una perspectiva micro y un ecosistema comunicacional particular, los resultados son difícilmente generalizables sin establecer contrastes con estudios de apoyo en otros contextos. En esta misma línea, justificamos el abordaje de un solo medio entre la compleja ecología mediática cubana, ya que, al ser el único enclavado en la comunidad, es el que tiene en su misión institucional el tratamiento de nuestro objeto: el acontecer local.

Por último, se considera que la experiencia del investigador principal del proyecto como periodista de la emisora entre los años 2015 y 2017 permitió un mayor acercamiento antropológico con la dinámica de producción comunicativa del medio y su relación con la comunidad. 


\section{Radio Titán y la esfera pública de Mella: configuraciones socio- antropológicas}

Aunque numerosos estudios sobre la relación entre medios y públicos en Cuba (González, 2015; Rey, 2016; Ramírez, 2016) dan cuenta de profundas divergencias entre estos actores, la dinámica de la comunicación de masas en Mella se distingue por la cercanía entre el medio local y la comunidad. Para Castillo (2017), lo anterior se debe al surgimiento del medio como radio comunitaria a partir de un proyecto que logró movilizar a barrios y actores sociales en su consolidación.

Con las entrevistas a oyentes y radialistas fundadores de la radio comunitaria, se logró sustentar la premisa de que el proyecto fue una experiencia de animación sociocultural en un contexto difícil del municipio y del país. Cuando se funda la estación radiofónica corría el año 1992, contexto conocido en Cuba como Periodo Especial (Silva, 2010) debido a que se sufría el desabastecimiento de productos de primera necesidad y los efectos del derrumbe del Campo Socialista, principal socio comercial y político de Cuba.

Uno de los testigos del surgimiento de la radio en Mella ofrece un acercamiento testimonial al escenario histórico: "La radio la formamos para alegrar la vida en medio de apagones [falta de energía eléctrica] y la carencia de muchas cosas. No teníamos en Mella otra forma de matar el tiempo, por eso todo el mundo oía los altavoces o venía hasta el parque a participar en los programas y escuchar música. También la radio era una forma de conversar sobre nuestros problemas y cómo resolverlos, aunque fuera tentativamente" -Fundador de la Radio en Mella, entrevista realizada el 25 de mayo de 2017-.

Se estableció así un modelo de radio local aficionado, voluntario, horizontal y participativo que desarrolló una cultura de producción particularizada (programas de participación, informativos, musicales), también de recepción participativa y consumo a través de diversas formas y soportes (radio-receptores, altavoces) y espacios sociales (plazas, mercados, calles, barrios, negocios) (Caraballoso, 2014; Castillo, 2017).

La cultura de construcción participativa de los programas radiofónicos se mantiene solamente en aquellos dedicados al esparcimiento, y ha desaparecido casi por completo en aquellos espacios dedicados al acontecer local (Castillo, 2017). Lo anterior ha sido consecuencia de la institucionalización del proyecto a partir de 1995 por la Dirección 
Nacional de la Radio al adscribir la radio al modelo y políticas nacionales de comunicación social.

El modelo de comunicación social en Cuba se sustenta sobre algunos rasgos del modelo soviético en el que se consideró que los medios responden a la formación ideológica del pueblo (García, 2013). Aunque estas nociones han sido muy discutidas en la presente década -con resultados significativos como una nueva Política de Comunicación Social- para actualizar el modelo a los fines de la sociedad cubana y sus valores de democracia, aún persisten rezagos culturales (García, 2013; González, 2015).

Sin embargo, el caso de los medios locales merece una atención particularizada. Los medios del país se caracterizan por la gestión estatal, las políticas establecidas por el Instituto Cubano de Radio y Televisión y la supervisión del Partido Comunista de Cuba. Aunque los documentos rectores manifiestan que deben responder a los espacios sociales donde están enclavados, los procedimientos y especificidades definidas son generales, hecho que ha posibilitado que se gestionen de la misma forma que el resto de los medios provinciales, nacionales e internacionales en una evidente cultura de homogenización de procedimientos y rutinas para la gestión y producción de contenidos (Herrera, Saladrigas \& Garcés, 2015; Rey, 2016; Ramírez, 2016).

De acuerdo con las entrevistas realizadas y los informes de investigación del Departamento de Programación de la emisora estudiada, las influencias del modelo macro de comunicación en Cuba repercutieron negativamente en el contexto local: aunque se ha mantenido el alto índice de escucha, se dejó de considerar al medio como un espacio de concertación y debate sobre los problemas comunitarios (Jorge Luis Betancourt, fundador de la radio en Mella, entrevista personal, 9/01/2017). La siguiente gráfica (Figura 1) ayuda a comprender la divergencia entre los temas de la agenda mediática y los de la agenda pública local sobre tópicos de relevancia comunitaria. 
Figura 1. Composición de las agendas mediática y pública en tres periodos de 2017.

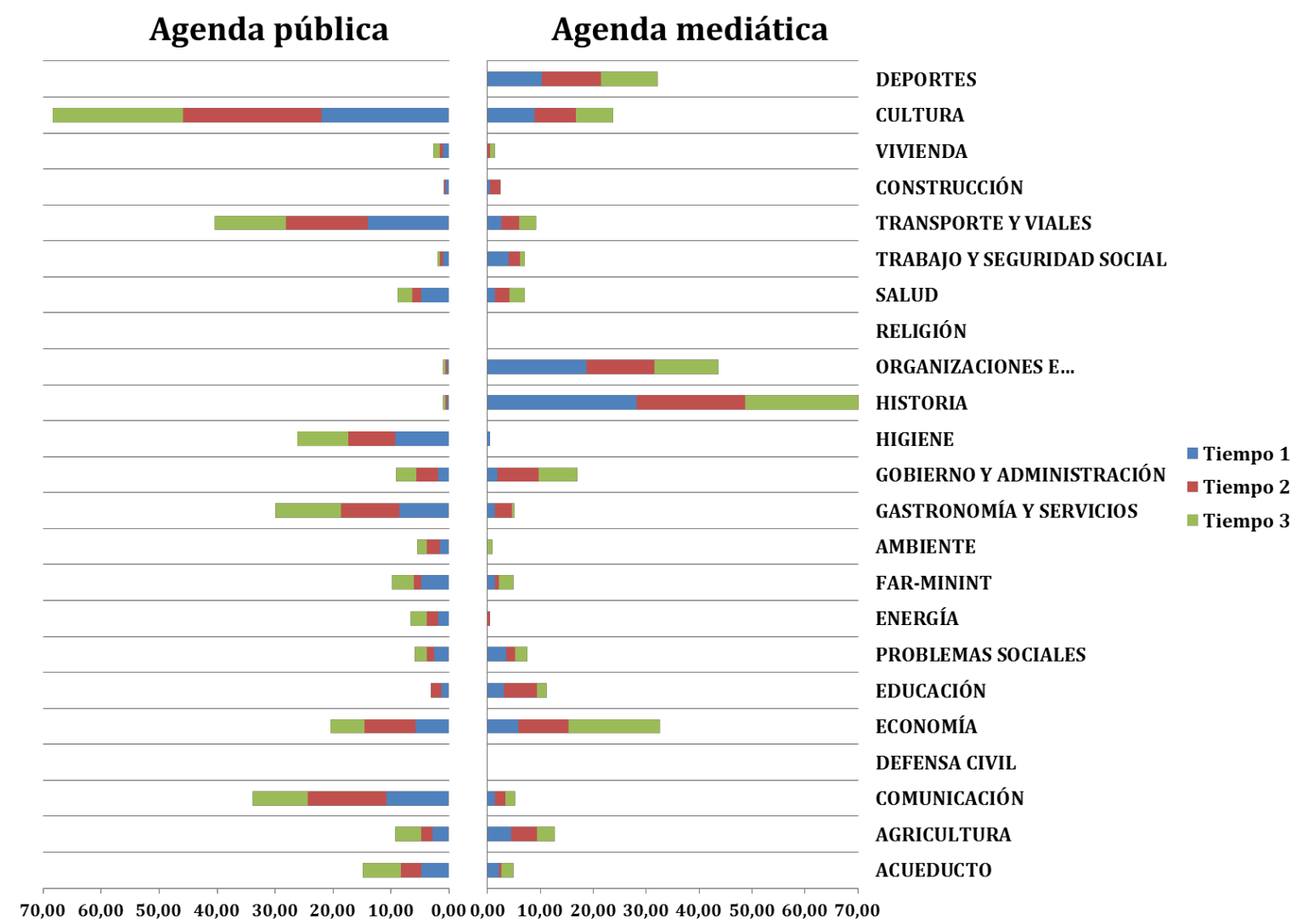

Fuente: Elaboración propia

Las condicionantes de estos resultados parten del propio contexto social. El mismo se caracteriza por complejas problemáticas entre las que sobresalen la salinización de los suelos y la carencia tecnológica para la diversificación agropecuaria, la complicada situación de los viales en zonas urbanas y de difícil acceso, la carencia de profesionales autóctonos (sobre todo en la rama de la salud, la educación y la industria), las condiciones de calidad del agua de consumo, poco desarrollo infraestructural, el transporte entre otras (Castillo, Villalón \& Delgado, 2017). Como puede apreciarse en la Figura 2, estas y otras problemáticas trascienden a la agenda pública y son constantes en la preocupación de los individuos.

La inmersión en el campo del municipio Mella desde el 2015, permitió la apropiación de algunos rasgos fundamentales de su antropología, los que hasta cierto punto explican las situaciones problemáticas descritas. La actividad económica fundamental del municipio es 
la industria azucarera, la cual representa más del 90\% de la economía local. Proviene del origen comunitario hace más de un siglo y fue gestada por emigrantes suecos que tejieron una impronta en la educación, el arte de la plástica (género naif), la ganadería y la producción de azúcar (Almenárez, 2016).

A la segunda década del siglo XXI, el territorio llega con una población cercana a los 35 mil habitantes y con un conjunto de 35 asentamientos humanos dispersos en territorios semiáridos, montañas y mogotes y distribuidos geográficamente en 332,7 kilómetros cuadrados. Algunas de estas comunidades son de difícil acceso por las condiciones de los caminos y las calles. Los últimos se realizaron hace más de cuatro décadas en la mayoría de los casos y persisten sin que se desarrollen revisiones y mantenimiento sistemáticos (Almenárez, 2016).

Los informes de investigación del medio evidencian que cada vez existen menos aparatos de recepción radiofónica en las comunidades, sin posibilidad de adquirir nuevos dado que en el país no se comercializan asiduamente. Esta carencia la ha resuelto la comunidad a partir de la cultura de amplificación gestada en tiempos de la fundación de la radio, por lo que es muy común que los vecinos amplifiquen la señal de la emisora para todo el barrio y que se escuche el medio en centros de trabajo, pequeños negocios y espacios públicos como paradas de ómnibus y plazas (Castillo, 2017).

Fundamentalmente en los territorios rurales, la radio compite con otras emisoras. Lo anterior está relacionado con la ubicación del municipio Mella y sus fronteras con cinco territorios no solo de la provincia Santiago de Cuba a la que pertenece, sino con otras dos. Las personas de las localidades más alejadas del centro del municipio mantienen una estrecha relación con los municipios más cercanos y en algunos casos aflora mayor identificación con los mismos.

Se comprobó a partir de observaciones y entrevistas que en los territorios montañosos más alejados existe dificultad con la recepción de la señal y las principales preocupaciones sociales coinciden con las limitaciones que encuentran en el curso material de su vida. Por otra parte, la lejanía, ausencia de teléfonos y otros mecanismos de retroalimentación entre el medio y estas comunidades, ha posibilitado que se establezcan otros espacios para la discusión de sus problemáticas. 


\section{La agenda mediática y sus relaciones antropológicas con la sociedad local}

A partir de los resultados de estudios precedentes y las técnicas aplicadas, se determinó la inclinación hacia temas poco conflictivos respecto a la realidad local en el encuadre de los asuntos institucionales en la agenda del medio; y el marcado carácter experiencial, de índole material (necesidades comunitarias) y crónico (distendidos en el tiempo) de los temas de preocupación pública (Castillo, Villalón \& Delgado, 2017). La contradicción entre los temas destacados por las agendas comprueba la mediación de un conjunto de prácticas y estructuras sociales en sus mecanismos de relación.

La agenda de Radio Titán recibe un conjunto de mediaciones sobre la entrada y jerarquización de los asuntos que integran sus prioridades temáticas. A partir de las técnicas aplicadas se elaboró un esquema de influencias que facilita la comprensión de los procesos antropológicos de conformación de la agenda mediática.

Figura 2. Modelo de entrada y encuadre de los temas en la agenda mediática.

\begin{tabular}{|c|}
\hline $\begin{array}{c}\text { Directrices Nacionales: Objetivos del } \\
\text { Trabajo Político, Política Informativa, } \\
\text { Envios del ICRT. } \\
\text { CULTURAMEDIATICAMACRO }\end{array}$ \\
\hline
\end{tabular}

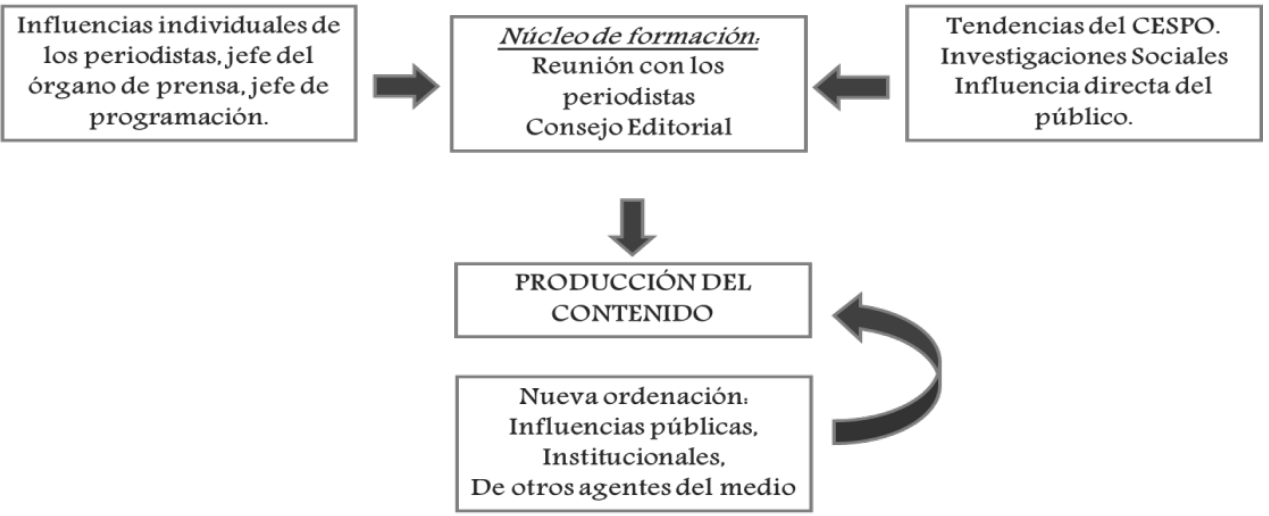

Fuente: Elaboración propia

Las mediaciones altamente significativas de la cultura mediática macro en Cuba y sus aparatos (leyes, normativas, circulares) se imponen sobre el resto de los mecanismos propios del medio para la conformación de la agenda, lo cual limita la relación significativa con los temas de relevancia pública comunitaria al proponer directrices generalizadas de gestión, que sin embargo son culturalmente asumidas sin atemperarse a la realidad local en la 
mayoría de los casos. Ello ha propiciado que los criterios de noticiabilidad, el carácter institucional de los temas tratados, el compromiso político entre otros rasgos distintivos de su formación, coincidan con las definiciones de la cultura comunicativa nacional y sus prácticas de producción (García, 2013; Rey, 2016; Herrera, Saladrigas \& Garcés, 2015; Ramírez, 2016).

También existen prácticas propias que pueden modificar la entrada o encuadre de algunos asuntos en la agenda a partir de la visión, necesidad y posibilidad de los profesionales de proponer algún tema. Por ejemplo, la escasez histórica de periodistas en el medio ha conllevado a que otros realizadores asuman la función y por tanto se sientan con la necesidad y el derecho de intervenir en la conformación de la agenda. Esta práctica se ha asentado a partir de las contradicciones afloradas en el devenir histórico de la emisora.

Los profesionales comparten una autoimagen de mediadores entre el público y las instituciones políticas y de gobierno, de ahí que den por sentado que el medio representa los intereses de la comunidad. Empero, en la práctica la balanza se inclina hacia los asuntos de interés institucional. Se considera que existe influencia pública a partir de las directivas nacionales, provinciales y locales porque se entiende que "estas representan las demandas del Estado Cubano y, en un contexto político-social como el de Cuba, el Estado es el pueblo" (Damaris Pérez, Jefa de Programación, entrevista personal, 25/05/2017). La afirmación anterior ayuda a comprender la imposición del modelo macro de comunicación sobre la experiencia comunicacional comunitaria.

Por su parte, las técnicas utilizadas mostraron la alta participación pública en los marcos institucionales de la emisora a través de cartas, llamadas telefónicas, notas y visitas. La mayor cantidad de estas manifestaciones participativas son para solicitar saludos, felicitaciones y temas musicales. Con lo cual se corrobora que la funcionalidad atribuida al medio por el público no se concibe en una primera instancia como un espacio para la discusión colectiva de los asuntos de relevancia pública.

Muy pocas veces los asuntos que se proponen públicamente se incluyen directamente en agenda, pues los actores mediáticos tienden a considerar como más eficientes los mecanismos que utilizan para representar a la agenda pública local (Boletines del Centro de Estudios Políticos y de Opinión del Partido Comunista de Cuba en el territorio, 
Investigaciones Sociales del medio entre otros), aunque ninguno de ellos depende de la participación directa de la ciudadanía en la formación de la agenda mediática.

Existe una representación colectiva entre los profesionales de la radio de que la realidad noticiable del municipio es pobre y por tanto cualquier información es digna de ser tenida en cuenta. Por consiguiente, las funciones del medio que más se potencian son la divulgativa y el sostenimiento de los valores culturales comunitarios, haciéndose a un lado otras como la vigilancia del entorno y la responsabilidad social para la solución de los problemas comunitarios. Esta práctica cultural constituye una de las más importantes en la explicación de las relaciones no significativas entre la agenda mediática y los intereses públicos.

Las relaciones socioculturales al interior del medio configuran el uso de las fuentes. De ellas, las institucionales son las más utilizadas (89 \%) (Castillo, Villalón \& Delgado, 2017), lo que corrobora la inclinación institucional de las estructuras sociales de la agenda mediática en detrimento de las relaciones directas con la audiencia. La observación permitió comprobar una correlación entre esta tendencia y la cercanía de los actores mediáticos con las fuentes de información, las cuales en muchos casos son las que acuden cotidianamente al medio para solicitar coberturas o tratar un tema de interés, si bien es muy frecuente que primero pasen por el filtro de la Directora o Jefa de Programación para recibir el visto bueno.

Otra de las cuestiones que contribuye a la lejanía de los temas entre las agendas son las mediaciones organizacionales concernientes a las presiones de las estructuras jerárquicas y el modelo de dirección. En este sentido se ha referido que la directora del medio determina o aprueba durante la reunión de orientación a los periodistas, qué temas se tratan y cuáles no, aunque teóricamente estos pueden ser propuestos por cualquier actor mediático o el público, de ahí la importancia de sus mediaciones culturales individuales. La figura de la directora del medio muestra su compromiso con las estructuras políticas del municipio y las fuentes (instituciones, organismos) para el encuadre de los asuntos, lo que contribuye a explicar la inclinación de la agenda mediática hacia los intereses institucionales de la sociedad local.

De los 33 trabajadores, solamente 3 son del sector artístico (9\%), y la totalidad del personal periodístico al momento de la pesquisa (9 \%) ha cursado estudios superiores relacionados con la comunicación de masas. Este hecho contribuye con el arraigo significativo de la cultura comunicacional generada al interior del medio: "Cuando llegué recién graduada 
quise cambiar muchas cosas, pero la propia rutina de la emisora te envuelve, es como una maquinaria que es más fuerte que tú" (Lisandra Rodríguez, Periodista, entrevista personal, 25/05/2017).

\section{La relación entre las agendas desde el público comunitario}

El medio de comunicación como espacio de relevancia pública para la construcción de la realidad ha condicionado desde su fundación una cultura de recepción, consumo, participación y acción social a partir de su mediación en el entorno sociocultural del municipio.

En este aspecto, existe la opinión entre los comunitarios de que los mecanismos de gestión mediática priorizan temas que de alguna forma son de necesidad local (50 \% de los encuestados), aunque se reconoce que no siempre son de interés individual o colectivo.

Mientras unos pocos individuos manifiestan que es posible acceder a la programación radiofónica directamente, otros muestran desconocimiento de poder hacerlo, lo que contribuye a explicar por qué no se utiliza al medio como un espacio de discusión social: "Ellos le dan participación al pueblo con llamadas. Yo lo he hecho, pero no para tratar un tema en específico, sino para pedir que me rectifiquen determinada información que no he entendido o para que me orienten sobre algo que ya han tratado; pero sobre todo para saludar a mi familia o compañeros de trabajo" (Mujer, entre 61 y 70 años, en grupo de discusión 4 ; 23/03/2017).

Por su parte, el cuestionario corroboró los resultados cualitativos. Solamente el 22 \% ha solicitado el tratamiento de temas específicos alguna vez. La mayoría reconoce que no es una práctica frecuente. En los grupos de discusión varios trabajadores y funcionarios públicos manifestaron que por razones laborales se han personado en la emisora para solicitar un tema o intervenir directamente en la programación. Esta cuestión confirma la cercanía del medio con las instituciones, lo cual en determinadas situaciones crea una distención con la agenda pública.

En los grupos focales los participantes concordaron que la inmediatez respecto a los asuntos de última hora es positiva (actos históricos, facilitación social), no así respecto a los problemas de larga data en la preocupación pública -el transporte, la alimentación, los viales etc.). La aludida necesidad participativa de la comunidad se sustenta sobre la

Perspectivas de la Comunicación - Vol. 14 - No 1 - 2021 - pp. 231-272

Universidad de la Frontera - Chile 
proximidad social y cultural de los asuntos de importancia local. La encuesta aplicada confirmó que en este contexto se asimilan las situaciones conflictivas a través de varias fuentes. Los resultados estadísticos que se presentan a continuación (Figura 3) fueron validados por las técnicas cualitativas:

Figura 3. Espacios de socialización de los problemas locales.

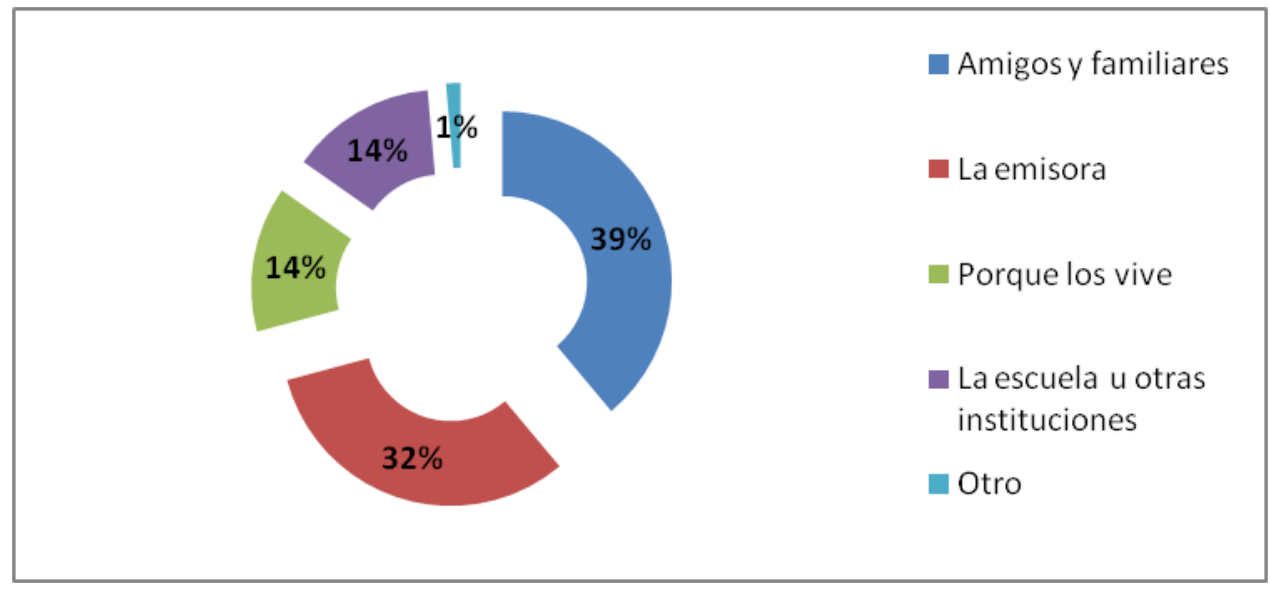

Fuente: Elaboración propia

A pesar de la variedad de espacios descritos, se comprobó que la vivencia de los problemas puede llegar a ser el filtro más importante para la inclusión de un tema en la agenda individual y colectiva, decidir su relevancia y excluir (temporalmente) algunos ante la compleja realidad municipal. Si bien la emisora mantiene un lugar favorable respecto a la orientación de algunas problemáticas (32 \%) para la ciudadanía, cualitativamente se determinó que no se le otorga una significación favorable como espacio de discusión sobre las problemáticas comunitarias más acuciantes.

Se verificó al analizar la cantidad de asuntos agendados por los individuos que, aunque pueden llegar a ser ocho ( $3 \%$ de los encuestados), la mayor cantidad de personas manifiesta máxima atención hacia los tres que considera más importantes. Estos asuntos guardan estrecha relación con aquellos que son reconocidos como temáticas sobre las que se tiene especial necesidad de conocimiento y profundización.

Las técnicas aplicadas permitieron comprobar que las características de reconocimiento social de los problemas locales han generado procesos antropológicos para la formación de 
la agenda pública a partir de filtros como la naturaleza experiencial y material de los problemas y su cronicidad sobre el mundo de la vida. La figura ilustra los temas sobre los que la audiencia precisa información durante el periodo de estudio:

Figura 4. Asuntos locales sobre los que se tiene necesidad de orientación.

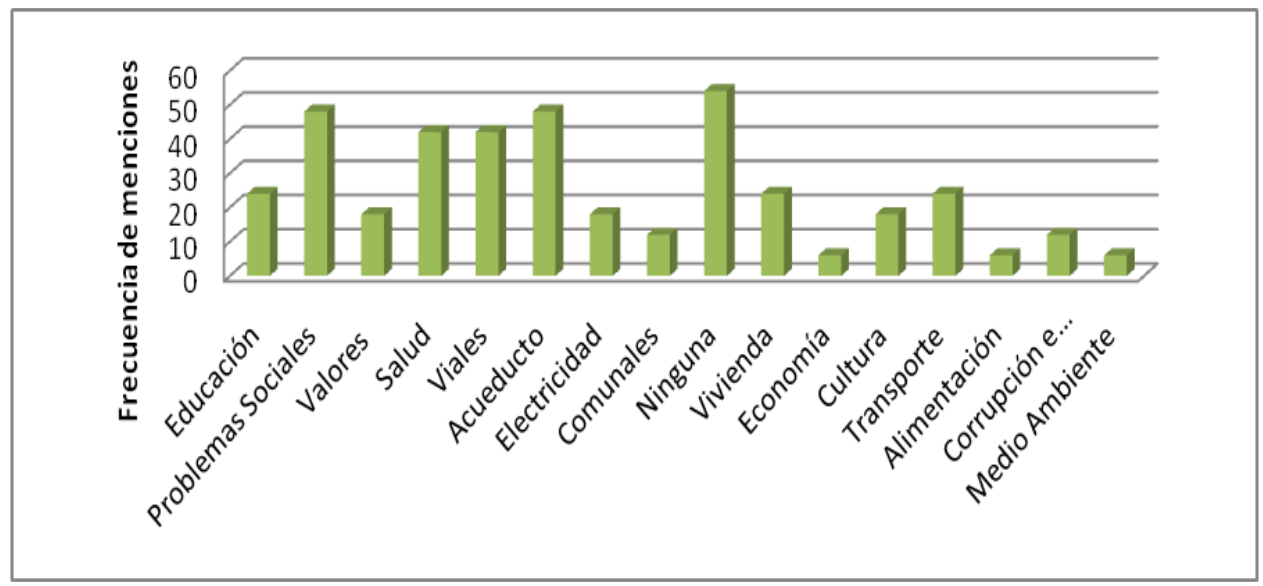

Fuente: Elaboración propia

Existe el habitus de que los individuos acudan a sus fuentes de información y los espacios socializadores (Figura 4) sobre la realidad comunitaria, en busca de información sobre estos asuntos.

Las dinámicas grupales permitieron concluir que el proceso de socialización de problemáticas a partir de la comunicación interpersonal constituye una fuente imprescindible para el aprendizaje y definición social, y permanencia en la agenda pública de los asuntos. La siguiente opinión contribuye a entender la significativa magnitud de su efecto socializador, dialógico y conformador del consenso social comunitario: "En Mella se habla cotidianamente de los problemas. Ahora mismo yo venía y vi a un niño con varicela cogiendo sol, descalzo y comenzó toda una disertación entre los que estaban por allí sobre eso y la gente compartió lo que sabía y su opinión. Se habla y se oye de todo" (Hombre, entre 41 y 60 años, en grupo de discusión $3 ; 15 / 03 / 2017$ ).

Respecto al interés por los asuntos locales se confirmó que los ciudadanos tienen alto compromiso con su comunidad ( $94 \%$ de los encuestados), lo cual se relaciona con el objetivo de permanecer informado (46 \%) a fin de hacer estallar las alarmas personales y colectivas 
ante una nueva problemática. Aunque, como se ha explicado, esta no es la funcionalidad práctica otorgada por los comunitarios al medio.

En relación con el contenido mediático, el $40 \%$ de los encuestados manifiesta inconformidad respecto a su agenda y considera que puede mejorarse. Un porcentaje similar cree que no se parece a la comunidad (38\%), frente al $62 \%$ que afirman lo contrario. Si bien estos resultados no son del todo desfavorables, la principal funcionalidad atribuida al medio es el entretenimiento, por lo que los individuos están valorando la representación de los valores comunitarios en el aspecto cultural y evasivo y no precisamente en el tratamiento de los asuntos de la agenda pública.

Las cuestiones explicitadas guardan estrecha relación con la forma es que se asume la credibilidad del contenido. Aunque los índices son favorables en su generalidad (78 \%), la comunidad pone en duda este factor por diversas razones. La más significativa alude a que "el medio tiene mucho compromiso [con las instituciones del municipio] y por eso no se puede tratar toda la problemática con sus implicados, solo se dice una parte” (Hombre, entre 18 y 25 años, en grupo de discusión 2; 13/02/2017).

Lo anterior puede explicar la preferencia respecto a los tipos de programas. En este aspecto se destaca la atención sobre los variados (54\%) y los musicales (34\%), mientras que sobre los informativos es solo de un $50 \%$. Esto responde a que el solapamiento con que el medio presenta la realidad comunitaria ha creado una percepción de incapacidad mediática e institucional para la solución de los problemas: "En la emisora se tratan temas de interés. Se tratan, pero se notan muchas justificaciones que no convencen a nadie. El problema está en la respuesta que quiere la población, eso determina hasta qué punto se considera creíble o no lo que se dice” (Mujer, entre 26 y 40 años, en grupo de discusión 5; 18/04/2017).

Respecto al consumo, la audiencia está dividida entre aquellos que lo hacen diariamente (28\%) y los que lo hacen esporádicamente (28\%). El resto fluctúan entre los que la escuchan solamente entre 1 y 2 veces a la semana ( $8 \%$ ) y los que lo hacen entre 3 y 4 veces ( 8 \%). Debe resaltarse que solamente manifiesta no escucharla nunca el $18 \%$, lo que indica que el consumo (a través de las prácticas de amplificación del medio) es significativo. 


\section{Discusión de los resultados}

El análisis realizado develó un patrón socio-antropológico de relaciones entre las agendas del medio y la ciudadanía local, lo que corrobora la necesidad de atender a su estructuración sociocultural. En este aspecto, el estudio etnográfico permitió una mayor apropiación de su complejidad, lo que valida su pertinencia para la profundización cualitativa. Al atenderse a las relaciones entre las agendas y no exclusivamente a los efectos mediáticos, el diseño metodológico logró mayor holismo al desprenderse de los sesgos del determinismo mediocentrista, o como le llama Thompson (1993), "falacia del internalismo".

En este sentido, los instrumentos cuantitativos y el conjunto de variables y modelos tradicionales de la Agenda Setting anclados a la etnografía, demostraron su factibilidad para el estudio de la comunidad. Los resultados cuantitativos, si bien no expresaron todas las contradicciones y características del objeto, sí contribuyeron a poner de relieve aspectos trascendentales. Los datos empíricos precedentes encontraron una mayor explicación con el presente estudio:

El modelo antropológico de comunicación local tiene algunas características que se imponen para explicar el objeto. Entre ellas sobresale el marcado carácter crónico de la agenda pública en torno a asuntos experienciales, considerados como problemáticas por satisfacer en función del bienestar de la vida comunitaria.

Por su parte, la agenda del medio se inclina en primera instancia a las estructuras e instituciones sociales y sus necesidades. Principalmente se avoca al sostenimiento del orden sociopolítico, lo que constituye una forma de conservación del orden social. Esta lógica tiene expresión desde lo macro, con la definición de políticas y un modelo comunicacional en el que se ha entendido a los medios como un instrumento de "establecimiento" del orden social. Aunque las recientes directivas de la nueva Política de Comunicación Social pretenden hasta cierto punto revertir esta concepción, persisten rezagos culturalmente enraizados con una importante presión en la objetivación del modelo nacional de comunicación, que son apreciables en el medio local estudiado.

Sin embargo, la dinámica de la agenda pública en Mella corrobora un carácter activo de la audiencia comunitaria en la cual se han definido prioridades temáticas a partir de la experiencia, así como estructuras y específicas formas (rutinas, espacios sociales, formas de comunicar) para su contrato de acción social comunitaria. Para ellos, el medio no es un

Perspectivas de la Comunicación - Vol. 14 - No 1 - 2021 - pp. 231-272

Universidad de la Frontera - Chile 
espacio público para manifestar sus opiniones, en tanto sus estructuras no priorizan los asuntos crónicos de la agenda pública, a pesar de que satisface otras necesidades comunitarias. Por su parte, las dinámicas de relación entre la agenda mediática y la agenda pública están subordinadas a la estructuración sociocultural de las relaciones entre sus actores.

Los mecanismos descritos tanto en la formación de la agenda pública como en la agenda mediática han sido asentados históricamente. Lo anterior se evidencia a partir de varios estudios desarrollados en la comunidad (Castillo, Villalón \& Delgado, 2017; Muñiz, Duvergel \& Castillo, 2017) en los que se encontraron correlaciones nulas tanto en el nivel de objetos como en los atributos. Estas aproximaciones empíricas expresan el carácter restringido del "establecimiento de la agenda pública por el medio local” en la historia reciente de la sociedad comunitaria.

Los resultados empíricos validaron la pertinencia de la estrategia de triangulación implementada. Esta última, concibió a los resultados cuantitativos como una aproximación a la manifestación de las relaciones entre las agendas en la realidad comunitaria, y su explicación a través de la inmersión desde técnicas cualitativas. Por otro lado, la etnografía ubicó a los resultados cuantitativos y cualitativos sobre la relación entre las agendas abordadas, en el marco de una lógica sociocultural comunitaria, que permitió una mayor apropiación del fenómeno como parte de lo social-cultural. Esta doble triangulación comprobó la pertinencia de la complementariedad entre los paradigmas positivista e interpretativo y actuó como instrumento de profundización sobre el núcleo de lo socialcultural desde una vía diferente a la estrategia de explicación por adición de variables y fenómenos concomitantes al proceso de selección de agendas, que ha sido característico de la Agenda Setting.

En el artículo seminal de la teoría, McCombs y Shaw (1972), fundamentaron la pertinencia psicologista de la investigación de agenda setting; sin embargo, su evolución ha demostrado un consistente aparataje y resultados de corte sociológico. Nuestra propuesta desde la antropología ha complementado algunas de sus carencias más discutidas (mediacentrismo, cuantitativismo, escasa atención a las relaciones micro-macro sociales, etc.) dando cuenta de un mayor holismo al integrar la comprensión del proceso en sus dimensiones humanas, sociales, históricas y culturales, lo que constituye un nuevo sentido de complejidad para la teoría. Lo anterior valida la pertinencia de metodologías convergentes en las que lo 
cuantitativo y lo cualitativo se triangule en función de un resultado más holístico y profundo; y un posicionamiento epistemológico más centrado en las relaciones socioculturales del fenómeno, que en sus consecuencias (efectos).

\section{Conclusiones}

La Teoría de la Agenda Setting ha desarrollado su expansión a partir de la implementación empírica y la inclusión de objetos y categorías adyacentes a su fenómeno central (el establecimiento de la agenda pública). No ha existido una línea de análisis articulada que atienda a las carencias epistemológicas de sus paradigmas y posicionamientos y, por tanto, genere una nueva lógica de profundización más allá de la inclusión de campos conexos y variables. Indudablemente, la reflexión crítica sobre estas columnas vertebrales de su constitución teórica (positivismo, empirismo, media centrismo, funcionalismo etcétera), constituye un camino ineludible para generar una episteme de mayor consistencia.

Los estudios precedentes y exploratorios constataron desde el trabajo de campo la necesidad de la inmersión cualitativa y contextualizada como complemento de las metodologías tradicionales positivistas, a fin de la apropiación del fenómeno de relación entre las agendas mediática y pública en tanto hecho sociocultural. Esto implica abordar las relaciones entre distintos actores en su sentido estructural, cultural y simbólico, construidas en el devenir histórico de la sociedad y su vida cotidiana.

Particularmente, la etnografía facilitó la profundización investigativa contextualizada, permitiendo captar la complejidad general del fenómeno a partir del contacto directo entre el investigador y el objeto de estudio. También la pertinencia de triangular datos cuantitativos y cualitativos para mayor comprensión.

El trabajo empírico desarrollado en Mella corroboró la pertinencia de atender al enfoque de la relación entre agendas y no únicamente al "establecimiento de la agenda". Con ello, la necesidad de abandonar el "mediacentrismo" para comprender un fenómeno que puede tener miles de objetivaciones en dependencia de las lógicas antropológicas de las sociedades, grupos o campos sociales donde se estudie. También la pertinencia de la investigación cualitativa como complemento de los resultados cuantitativos y la necesidad desarrollar en paralelo una línea de reflexión epistémica. 
De acuerdo con los resultados del estudio, los rasgos antropológicos de la relación entre los actores sociales -en este caso el medio y el público- "configuran" la relación entre estas agendas al ser el marco de objetivación de todo el proceso. Esta conclusión nos conlleva a pensar que puede definirse como un nuevo nivel de la Agenda Setting, un "nivel configuracional y fenomenológico", idea que se desarrollará en próximos trabajos.

\section{Conflicto de interés}

Los autores declaran que no existe conflicto de interés. 


\section{Referencias bibliográficas}

ALMENÁREZ, N. (2016): Metodología para la Inclusión Social de Tecnologías en el desarrollo sostenible de comunidades rurales del Consejo Popular Regina [Tesis de Maestría sin publicar, Universidad de Holguín].

ANDRÉU, J. (2012): La descodificación de la agenda: Un modelo analítico para el conocimiento manifiesto y latente de la agenda pública. Intangible Capital, 8(3), pp. 520547 .

ARDÈVOL, A., GIL, H. \& MCCOMBS, M. (2020): Orígenes y desarrollo de la teoría de la agenda setting en Comunicación. Tendencias en España (2014-2019). Profesional de la información, 29(4), pp. 1-23.

ARDÈVOL, E. (1998): Por una antropología de la mirada: etnografía, representación y construcción de datos audiovisuales. Revista de Dialectología y Tradiciones Populares, LIII(2), pp. 1-24.

ARUGUETE, N. (2015): El poder de la agenda: política, medios y públicos. Argentina, Biblos.

BANTIMAROUDIS, P. \& ZYGLIDOPOULOS, S. (2014): Cultural Agenda Setting: Salient Attributes in the Cultural Domain. Coporate Reputation Review, 17(13), pp.183-194.

BERRA, N. \& FERNÁNDEZ, G. (2005): Un modelo para el estudio de los medios y la construcción social de la realidad. Actas de la III Jornadas Nacionales de Investigadores en Comunicación "Comunicación: campos de investigación y prácticas". Ciudad México.

BOUZA, F. (2012): Metodologías de Agenda en el estudio en el estudio de la opinión pública como base de la comunicación política. RedMarka, 5(8), pp.41-54.

CALDERÍN, G. (2013): Al Santiago de siempre. La Habana, En Vivo.

CARABALlOSO, E. (2014): La palabra en el aire. Memorias de la radio santiaguera. Santiago de Cuba, Editorial Oriente.

Perspectivas de la Comunicación - Vol. 14 - No 1 - 2021 - pp. 231-272

Universidad de la Frontera - Chile 
CASERMEIRO, A. (2004): Los medios en las elecciones: la Agenda Setting en la Ciudad de Buenos Aires. Argentina, Educa.

CASTILLO, Y. (2015): El mundo agendado. Influencia de las condiciones contingentes en el establecimiento de la agenda de temas internacionales [Tesis de licenciatura, Universidad de Oriente, Cuba].

(2017): De comunitario a local: el caso de Radio Titán. Santiago, (142), pp. 125-140.

(2018): Hacia una interrelación dialógica de las agendas de asuntos locales: el caso de Radio Titán y la agenda pública del municipio Mella. [Tesis de Maestría, Centro de Estudios Sociales Cubanos y Caribeños, Universidad de Oriente, Cuba].

CASTILlO, Y., VILLALÓN, G. \& DELGADO, A. N. (2017): Relación entre los intereses temáticos entre medios y públicos en municipalidades cubanas. Un estudio de caso. Question, 1(54), pp. 116-136.

CASTRO, D. (2014): Agenda-setting e Internet: tendências e perspectivas de pesquisa. [Tesis de maestría, Universidad de Brasilia, Brasil].

CHARRON, J. (1995): Los medios y las fuentes. Los límites del modelo de Agenda Setting, en G. Gauthier, A. Gosselin \& J. Mauchon, Comunicación y Política. Barcelona, Gedisa.

COHEN, B. (1963): The press and foreign policy. Princeton (NJ), Princeton University Press.

DADER, J. L. (1991): La canalización o fijación de la "agenda" por los medios. Opinión pública y comunicación política. España, Eudema Universidad.

DEARING, J. W. \& ROGERS, E. (1996): Agenda-setting (vol. 6). Estados Unidos, Sage publications.

FERNÁNDEZ, M. \& TARDIVO, G. (2016): La Sociología de la Comunicación y la Mass Communication Research: tradición y actualidad. Espacio Abierto, 25(3), pp. 1-15. 
GALLEGO, J. R. (2015): Las carencias sociológicas de la Teoría de la Agenda Setting: una crítica poco atendida. Alcance, 4(6), pp. 98-122.

(2016): Cambio social y estudios de agenda. Análisis crítico y algunas ideas para el estudio del caso cubano. Comunicación y Sociedad, Nueva Época, (25), pp. 183-207.

(2017): Existe pero no se ve... Investigación de Agenda Setting en América Latina. La Trama de la Comunicación, 21(2), pp. 87-108.

GARCÍA, J. (2013): Revolución, socialismo, periodismo. La prensa y los periodistas cubanos ante el siglo XXI. La Habana, Pablo de la Torriente.

GONZÁLEZ, L. (2015): Hacia un nuevo modelo comunicativo: escenarios posibles para Cuba. Entrevista con el experto cubano José Ramón Vidal. Razón y Palabra, (92), pp. 1-22.

GUBER, R. (2004): La Etnografía. Método, campo y reflexividad. Buenos Aires, Norma.

HERNÁNDEZ, R., COLLADO, C. \& BAPTISTA, P. (2014): Metodología de la Investigación (Sexta edición). México, McGraw Hill.

HERRERA, D., SALADRIGAS, H. \& GARCÉS, R. (2015): Modelo de televisión local en Cuba. Una investigación pionera a sus rasgos distintivos. Razón y Palabra, (92), pp. 1-41.

KIM, Y., KIM, Y. \& ZHUO, S. (2017): Theoretical and methodological trends of agendasetting theory. Agenda Setting Journal, 1(1), pp. 5-22. doi10.1075/asj.1.1.03kim

LIPPMANN, W. (1922): La opinión pública. Argentina, Compañía General Fabril Editora.

MARTÍN-BARBERO, J. (2005): Medios y culturas en el espacio latinoamericano. Pensar Iberoamérica, (5), pp. 1-18.

MCCOMBS, M. E, SHAW, D. L., \& WEAVER, D. H. (2014): New directions in agendasetting theory and research. Mass communication and society, 17(6), pp. $781-802$. 
MCCOMBS, M. E. \& SHAW, D. L. (1972): The agenda setting function of mass media. Public Opinion Quarterly, 36(2), pp. 176-187.

MCCOMBS, M. E. \& VALENZUELA, S. (2014): Agenda-Setting Theory: The Frontier Research Questions. Estados Unidos, Oxford handbooks online.

10.1093/oxfordhb/9780199793471.013.48

MCCOMBS, M. E. (2006): Estableciendo la agenda: el impacto de los medios en la opinión pública y en el conocimiento. Barcelona, Paidós.

MUÑIZ, V. \& CASTILLO, Y. (2016): Intermedia agenda setting en medios nacionales cubanos: casos Granma y Noticiero Nacional de Televisión. Estudio sobre temas no experienciales. Question, 1(51), pp. 445-467

(2018): Estudios de agenda setting en Cuba: propuesta de metodología para un desarrollo posible. Empiria, (41), pp. 127-155.

MUÑIZ, V., DUVERGEL, M. \& CASTILLO, Y. (2017): Divergencia temática informativa entre la agenda del público y los medios locales en Cuba: un estudio de caso. Sphera Publica, 2(17), pp. 53-76.

MUÑIZ, V., FONSECA, R. Á. \& CABALLERO, D. (2016): Formación de la Agenda Pública en Santiago de Cuba durante el año 2015. Chasqui, (132), pp. 373-392.

OROZCO, G. (2010): Hacia una cultura de participación televisiva de las audiencias. Ideas para su fortalecimiento. Comunicación, media y consumo, 19(7), pp. 13-31.

OSORIO, F. (2002): Propuesta para una antropología de los mass media. Cinta de Moebio, (13), pp. 115-125.

PAREDES, R. (2005): Investigación Multidisciplinaria: voces en el aire, apuntes para conocer la radio. Cinta de Moebio, (22), pp. 137-144. 
RAMÍREZ, J. (2016): Prácticas culturales y Televisión de proximidad cultural. Estudio de caso en Crisol de la Nacionalidad Cubana (CNC TV), Bayamo [Tesis Doctoral, Centro para el Desarrollo Integral de la Cultura (CEDIC), Universidad de Oriente].

REY, L. M. (2016): Fundamentos sociológicos para incrementar la participación de la comunidad en la creación televisiva [Tesis Doctoral. Centro de Estudios Comunitarios de la Universidad Central Martha Abreu de Las Villas].

RODRÍGUEZ, R. (2004): Teoría de la Agenda-Setting. Aplicación a la enseñanza universitaria. España, Observatorio Europeo de Tendencias Sociales.

ROSEMBERG, L. (2017): Etnografía del trabajo periodístico. Apuntes sobre la inserción del investigador en la sala de redacción de un diario argentino. Comunicación y Sociedad, (28), pp. 87-109.

SHOEMAKER, P. \& REESE, S. (2014): Mediating the message in the 21st century: A media sociology perspective. Estados Unidos, Routledge.

SILVA, A. (2010): El Periodo Especial. En J. C. Cantón y A. Silva, Historia de Cuba: liberación nacional y socialismo (pp.209-252). La Habana, Editorial Pueblo y Educación.

TAMAYO, M. \& CARRILLO, E. (2005): La formación de la agenda pública. Foro Internacional, XLV(4), pp. 658-681.

THOMPSON, J. (1993): Ideología y cultura moderna. La Habana, Félix Varela.

TORRE, R. (1997): La comunicación intersubjetiva como fundamento de la investigación etnográfica. Comunicación y Sociedad, (30), pp. 149-173.

TRIGUEROS, J. \& LACASA-MAS, I. (2018): Colloquy with Maxwell McCombs at the University of Texas at Austin: agenda setting, a limitless theory in a connected world. Church, Communication and Culture, 3(1), pp. 53-74.

https://doi.org/10.1080/23753234.2018.1430513 
TRINDADE, E. \& SILVA, J. (2009): Antropología, comunicación e imágenes: alternativas para pensar la publicidad y el consumo en la contemporaneidad. Pensar la publicidad, III(1), pp. 203-218.

VARA, A. (2001): La influencia de los partidos políticos en la construcción de la agenda mediática y el rol de los periodistas como mediadores sociales. Aproximación teóricopráctica a las teorías de la agenda setting y de la agenda building [Tesis de doctorado. Universidad de Navarra, España].

VARGO, C. (2018): Fifty years of agenda-setting research. New directions and challenges for the theory. Agenda setting Journal, 2(2), pp. 105-123.

https://doi.org/10.1075/asj.18023.var

WOLF, M. (2004): La investigación en la comunicación de masas. Barcelona, Paidós. 